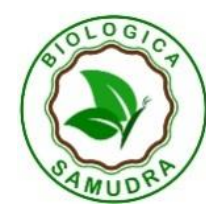

\title{
INVENTARISASI JENIS HAMA DAN CARA PENGENDALIANNYA DI PEMBIBITAN KELAPA SAWIT (Elaeis guineensis Jacq.) PT. PERKEBUNAN NUSANTARA IV DOLOK SINUMBAH
}

\section{Inventory of Pest Type and Its Control Way in Palm Oil Nursery (Elaeis guineensis jacq.) PT Perkebunan Nusantara IV Dolok Sinumbah}

\author{
Kasa Nova Tripena Turnip ${ }^{1 *}$, Beni Al Fajar ${ }^{1}$ \\ 1Program Studi Biologi, Fakultas Teknik, Universitas Samudra, \\ Kampus Unsam Meurandeh, Langsa, 24415
}

Received: 15 Juni 2020;

KATA KUNCI KEYWORDS

ABSTRAK

ABSTRACT
Tanaman kelapa sawit, hama, pengendalian palm oil, pest, held

Produksi kelapa sawit (Elaeis guineensis.jacq) sebagai penghasil minyak nabati. tidak terlepas dari serangan hama yang menyebabkan penurunan produksi bahkan kematian tanaman. Tujuan penelitian ini untuk mengetahui jenis hama dan cara pengendaliannya di PTPN IV Dolok Sinumbah Simalungun Sumatera Utara. Penelitian menggunakan metode analisis deskriptif dengan purposive sampling, yaitu pengambilan sampling dengan cara menentukan kriteriakriteria tertentu dari sample. Berdasarkan hasil penelitian yang telah dilakukan ditemukan 6 spesies hama diantaranya Setothosea asigna, Calliteara horsfieldii Saunders, Metisa plana walker, Tirathaba mundella walker, Orytes rhinoceros, dan Tertacychus bimaculatus. Untuk pengendalian hama dilakukan secara fisik yaitu dengan pengutipan hama ulat, biologi menggunakan beberapa jenis tanaman inang bagi predator hama ulat bulu seperti bunga pukul delapan (turnea sabulata), secara kimia menggunakan decis2,5 EC.

The production of palm oil (Elaises Guinessis) as a vegetable oil producer is inseparable from pest attacks that cause the decrease in production even the death of the plant. The purpose of this practice is to know the type of pest and its way of control at PTPN Dolok Sinumbah Sumatera Utara. This research uses descriptive analysis method with purposive sampling, namely sampling by determining certain criteria of sample. Based on the results of research that has been done found 6 species of pests including Setothosea asigna, Calliteara horsfieldii Saunders, Metisa plana walker, Tirathaba mundella walker, Orytes rhinoceros, dan Tertacychus bimaculatus. For physical controls are done physically, with citate citular citations, biology using some types of hosts for pestrators of caterpillar pests such as flower tapeons at eight (Turnea Sabulata), chemically using Desic 2.5. 


\section{Pendahuluan}

Kelapa sawit (Elaeis guineensis.jacq) merupakan salah satu jenis tanaman yang termasuk dalam golongan palma dari family Arecaceae sebagai penghasil minyak nabati yang biasa digunakan dalam rumah tangga, industri makanan, kosmetik maupun bahan bakar nabati (biodiesel) (Yuna dan Mardina, 2019; Rindarkoko, 2012). Kelapa sawit sangat diminati untuk dikelola dan ditanam dalam skala kecil oleh masyarakat maupun skala besar oleh perusahaan-perusahaan perkebunan (Surbakti dkk, 2019). Komoditi kelapa sawit memiliki andil besar dalam menghasilkan pendapatan asli daerah (Sitorus dan Mardina, 2020), produk domestik bruto, dan kesejahteraan masyarakat. Lebih lanjut Siradjuddin (2015) menyatakan bahwa kegiatan perkebunan kelapa sawit telah memberikan pengaruh eksternal yang bersifat positif bagi wilayah sekitarnya terhadap aspek sosial ekonomi antara lain: 1) peningkatan kesejahteraan masyarakat sekitar; 2) memperluas lapangan kerja dan kesempatan berusaha; 3) memberikan kontribusi terhadap pembangunan daerah.

Dalam usaha budidaya tanaman kelapa sawit, setiap perusahaan tidak terlepas dari faktor - faktor yang menghambat perkembangan, pertumbuhan dan masa produksi tanaman sawit, seperti salah prosedur dalam pemeliharan, pemupukan, pengendalian serangan hama. Serangan hama pada tanaman kelapa sawit dapat menyebabkan penurunan produksi bahkan kematian tanaman (Nasution dkk, 2019). Hama dapat menyerang tanaman kelapa sawit mulai dari pembibitan hingga tanaman menghasilkan (Fauzi, 2012) Beberapa jenis hama penting yang menyerang tanaman kelapa sawit misalnya hama babi, tikus, kumbang tanduk, maupun hama ulat pemakan daun kelapa sawit (UPDKS) (Hakim, 2007). Selanjutnya Pusat Penelitian Kelapa Sawit (2002) menyatakan bahwa permasalahan penting dalam perkebunan tanaman kelapa sawit adalah serangan ulat pemakan daun yang menyerang baik pada periode tanaman belum menghasilkan (TBM) maupun tanaman menghasilkan (TM). Penurunan jumlah produksi kelapa sawit akibat serangan hama tersebut dapat mencapai $40 \%$ atau sekitar 6,4 ton/ha.

\section{Metode Penelitian}

Penelitian dilaksanakan di areal perkebunan PTP. Nusantara IV Kebun/Pabrik Dolok Sinumbah Simalungun Sumatera Utara, tepatnya dibagian afdeling 1 dengan luas $911 \mathrm{Ha}$, dan memiliki dua areal yaitu TM (48 Blok) dan TBM (9 Blok). Selanjutnya dilakukan identifikasi hama yang tertangkap dilapangan yang menggunakan buku identifikasi serta jurnal-jurnal. Penelitian ini dimulai pada Januari hingga Februari 2020. Bahan dan alat yang digunakan adalah hama, buku data, buku acuan identifikasi (hama dan penyakit tanaman), stoples dan penggerek daun kelapa sawit. 
Adapun metode yang digunakan dalam penelitian ini adalah metode analisis deskriptif dengan purposive sampling, yaitu pengambilan sampling dengan cara menentukan kriteria-kriteria tertentu dari sample dengan memilih areal tanaman menghasilkan (TM) pada blok A yang ditanam pada tahun 2005 dan areal tanaman belum menghasilkan (TBM) pada blok C Yang ditanam pada tahun 2015. Pengambilan sampling dilakukan di areal tersebut karna blok A pada TM dan blok $\mathrm{C}$ pada TBM paling banyak terkena serangan hama dari blok atau areal lainya.

\section{Hasil}

Dari hasil pengamatan yang dilakukan di Perkebunan PTPN IV Dolok Sinumbah Simalungun Sumatera Utara di lapangan didapatkan enam jenis hama. Jenis hama tersebut dibagi ke dalam dua ordo dan lima famili. Jenis-jenis serangga yang ada pada setiap ordo dapat dilihat pada Tabel 1.1.

Tabel 1.1 jenis- jenis serangga pada setiap ordo

\begin{tabular}{l|l|l|l|l}
\hline No & \multicolumn{1}{l}{ Ordo } & \multicolumn{1}{l}{ Family } & Genus & Spesies \\
\hline $\mathbf{1}$ & Lepidoptera & Limacodidae & Setothosea & Setothosea asigna \\
\hline $\mathbf{2}$ & Lepipdoptera & Lasiocampidae & Calliteara & Calliteara horsfieldii Saunders \\
\hline $\mathbf{3}$ & Lepidoptera & Psychidae & Metisa & Metisa plana walker \\
\hline $\mathbf{4}$ & Lepipdoptera & Pyralidae & Tirathaba & $\begin{array}{l}\text { Tirathabamundella } \\
\text { walker }\end{array}$ \\
\hline $\mathbf{5}$ & Coleopteran & Scarabaidae & Oryctes & Orytes rhinoceros \\
\hline $\mathbf{6}$ & Acarina & Tertachidae & Tertacychus & Tertacychus bimaculatus \\
\hline
\end{tabular}

\section{Pembahasan}

\subsection{Ulat api (Setothosea asignaVan Eecke)}

Setothosea asigna merupakan ulat yang hidup berkelompok, memakan daun mulai dari ujung kearah bagian pangkal daun hingga habis dan hanya menyisakan tulang daun atau lidi dan sering disebut gejala melidi. Dalam kondisi yang sangat parah tanaman akan kehilangan daun hingga 50\% - 90\% dan pohon menjadi mati. Anak daun pada ujung pelepah adalah bagian yang paling disukai hama ini. Umumnya gejala serangan dimulai dari daun bagian bawah hingga akhirnya helaian daun berlubang habis dan bagian yang tersisa hanya tulang daun saja. S.asigna mampu mengkonsumsi 300- 500 helai daun sawit perhari. Bekas serangan terlihat jelas seperti jendela- jendela memanjang pada helalian daun, sehingga akhirnya daun yang terserang berat akan mati kering seperti bekas terbakar (Pahan,2008). 


\subsection{Ulat bulu (Calliteara horsfieldii Saunders}

Calliteara horsfieldii Saunders ini sering ditemukan menyerang daun pada tanaman dewasa. Larvanya memiliki 4 pasang bulu panjang di punggung, berwarna kuning pucat, panjangnya bisa mencapai $50 \mathrm{~mm}$. Larva umumnya berada pada pelepah ke 25 (Manik,2012). Ulat muda biasanya bergerombol di sekitar tempat peletakkan telur dan mengikis daun mulai dari permukaan bawah daun kelapa sawit, serta meninggalkan epidermis daun bagian atas. Bekas serangan terlihat seperti jendela-jendela memanjang pada helaian daun.

\subsection{Ulat tirathaba (Tirathaba mundella walker)}

Pada tanaman kelapa sawit, Tirathaba dikenal sebagai hama penggerek tandan buah kelapa sawit di Indonesia yang menyebabkan fruit set rendah. Awalnya, hama ini akan menyerang bunga dan buah muda. Gejala serangan ditandai dengan adanya kotoran ulat berupa butiran-butiran berwarna merah tua kecoklatan kemudian mengering. Tirathaba umumnya mulai menyerang buah yang muda. Jika ditemukan serangan Tirathaba pada buah yang sudah matang, maka umumnya hampir keseluruhan tandan buah yang ada telah terserang oleh hama tersebut.

\subsection{Ulat kantong (Metisa plana walker)}

Ulat Kantong (Metisa plana Wlk) merupakan salah satu kelompok ulat pemakan daun kelapa sawit yang merugikan pada perkebunan kelapa sawit. Tanaman yang diserang ulat ini terutama pada tanaman dewasa seperti tanaman menghasilkan (TM), daun yang diserang metisa plana dapat mejadi kering seperti terbakar karna ulat saat memakan daun mengeluarkan cairan yang bersifat racun. Metisa plana merusak tanaman kelapa sawit dengan memakan daun tanaman untuk perkembangan tubuhnya dan untuk pembentukan kantongnya. Larva ulat kantong lebih suka memakan daun bagian atas dan daun bagian bawah untuk menggantung dan membentuk kantong. Kerusakan pada tanaman kelapa sawit akan terlihat secara jelas ketika sudah terjadi defoliasi sebesar $50 \%$. Kerusakan pada tingkat ini akan mengurangi hasil hingga 10 ton TBS/ha. (Ali et al., 2012).

\subsection{Kumbang tanduk (Orytes rhinoceros)}

Kumbang tanduk merupakan hama yang utama menyerang tanaman kelapa sawit di Indonesia, khususnya di areal tanaman belum menghasilkan (TBM) kelapa sawit. O. Rhinoceros menggerek pucuk kelapa sawit yang mengakibatkan terhambatnya pertumbuhan dan rusaknya titik tumbuh sehingga mematikan tanaman. Hama ini sangat merusak tanaman kelapa sawit dan tersebar luas di seluruh wilayah Indonesia hingga Asia Tenggara, Pasifik, dan daerah sentra pertanaman kelapa. O. rhinoceros terutama menyerang tanaman kelapa yang kurang terawat dan dapat menyebabkan kerusakan yang sangat serius. Gejala tanaman yang 
terserang nampak daunnya membentuk potongan segitiga akibat dimakan hama ini (Mawikere et al., 2007).

\subsection{Tungau merah (Tertacychus bimaculatus )}

Tungau merah (Tertacnychus bimaculatus) adalah hama yang menyerang daun pada perkebunan kelapa sawit. Tungau ini berukuran $0,5 \mathrm{~mm}$ hidup di sepanjang tulang anak daun sambil mengisap cairan daun sehingga warna daun berubah menjadi mengkilat berwarna kecoklatan. Hama ini berkembang pesat dan membahayakan dalam keadaan cuaca kering pada musim kemarau. Tertacnychus bimaculatus biasanya selalu ada pada setiap daun, baik daun pada tanaman yang sudah menghasilkan (TM) maupun tanaman belum menghasilakan (TBM). Tungau bersembunyi dibalik daun, serangan ditandai dengan adanya muncul bitnik kuning dipermukaan daun.

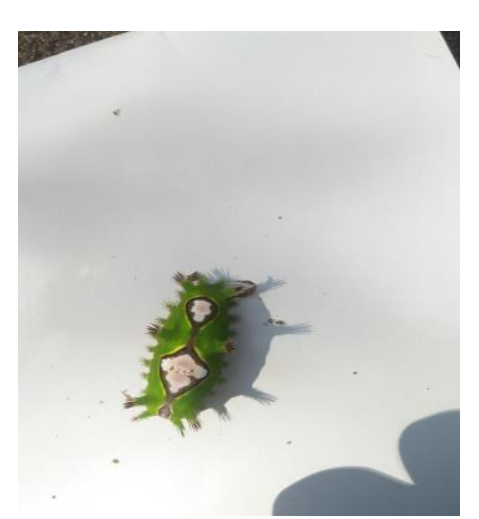

$\begin{array}{ll}\text { Klasifikasi } & \\ \text { Kindom } & \text { : Animalia } \\ \text { Filum } & \text { : Arthropoda } \\ \text { Kelas } & \text { : Insecta } \\ \text { Ordo } & \text { : Lepidoptera } \\ \text { Family } & \text { : Limacodidae } \\ \text { Genus } & \text { : Sethosea } \\ \text { Spesies } & \text { : Sethosea asigna Van Eecke }\end{array}$

Gambar 1. Sethosea asigna Van Eecke

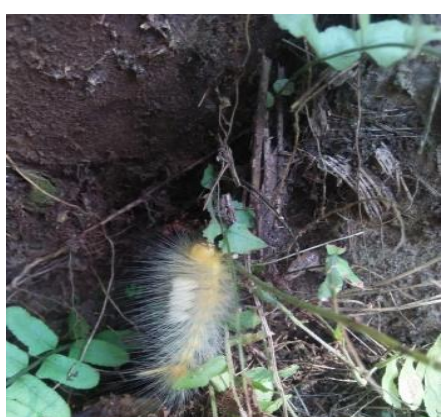

Kindom : Animalia

Filum : Arthropoda

Kelas : Insecta

Ordo : : Lepidoptera

Family : Lasiocampidae

Genus : Calliteara

Spesies : Calliteara horsfieldii Saunders

Gambar 2. Calliteara horsfieldii

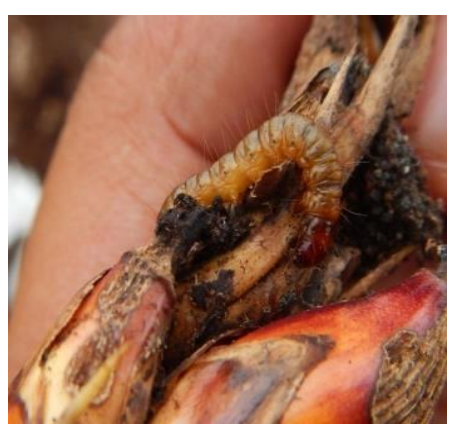

$\begin{array}{ll}\text { Kindom } & \text { : Animalia } \\ \text { Filum } & \text { : Arthropoda } \\ \text { Kelas } & \text { : Insecta } \\ \text { Ordo } & \text { : Lepidoptera } \\ \text { Family } & \text { : Pyralidae } \\ \text { Genus } & \text { :Tirathaba } \\ \text { Spesies } & \text { : Tirathaba mundella walker }\end{array}$

Gambar 3. Tirathaba mundella walker 


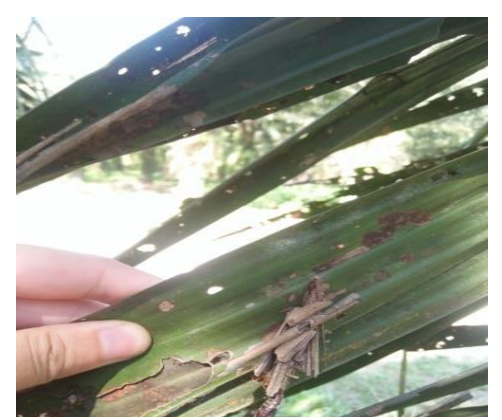

$\begin{array}{ll}\text { Kindom } & : \text { Animalia } \\ \text { Filum } & \text { : Arthropoda } \\ \text { Kelas } & \text { : Insecta } \\ \text { Ordo } & \text { : Lepidoptera } \\ \text { Family } & \text { : Psychidae } \\ \text { Genus } & : \text { Metisa } \\ \text { Spesies } & \text { : Metisa plana walker }\end{array}$

Gambar 4. Metisa plana walker

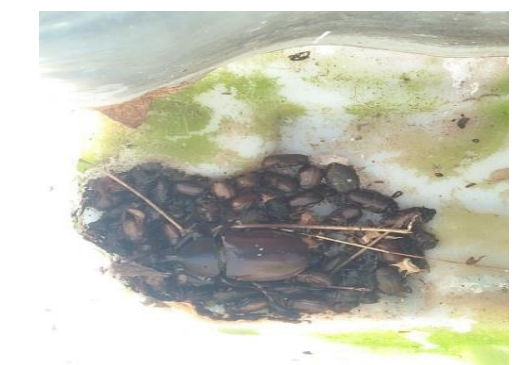

Gambar 5. Orytes rhinocer

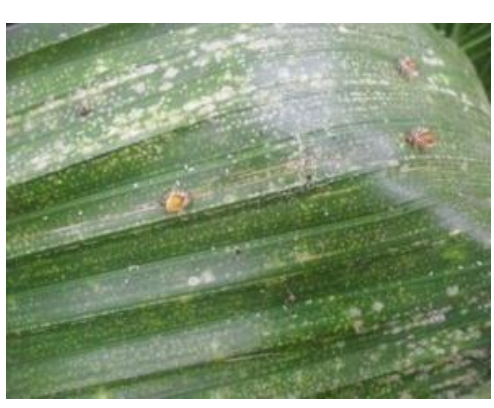

Gambar 6. T. bimaculatus

$\begin{array}{ll}\text { Kindom } & \text { : Animalia } \\ \text { Filum } & \text { : Arthropoda } \\ \text { Kelas } & \text { : Insecta } \\ \text { Ordo } & \text { : Coleoptera } \\ \text { Family } & \text { : Scarabaidae } \\ \text { Genus } & \text { : Orytes } \\ \text { Spesies } & \text { : Orytes rhinocer } \\ \text { Kindom } & : \text { Animalia } \\ \text { Filum } & : \text { Arthropoda } \\ \text { Kelas } & : \text { Arachinda } \\ \text { Ordo } & : \text { Acarina } \\ \text { Family } & : \text { Tertachidae } \\ \text { Genus } & : \text { Tertacychus } \\ \text { Spesies } & : \text { Tertacychus bimaculatus }\end{array}$

Pengendalian hama di PTPN IV Dolok Sinumbah Simalungun Sumatera Utara dilakukan dengan beberapa cara yaitu pysik atau mekanis pengutipan ulat kantong dan kepompong ulat api, pengumpulan pembersihan tempat berkembang biaknya. Secara Biologis dengan menggunkan organisme lain sebagai musuhnya yakni parasit organisme yang hidupnya tergantung dan merugikan organisme lain predator organisme pemakan serangga/hama. Dalam pengendalian hama secara biologis, ada beberapa jenis tanaman inang bagi predator hama yang beberapa diantaranya bisa tumbuh liar di lapangan. Untuk memaksimalkan manfaat dari tanaman-tanaman tersebut dapat dilakukan dengan menanam pinggiran jalan secara teratur sehingga selain bermanfaat mencegah serangga hama, juga bisa menambah estetika kebun. Tanaman yang digunakan seperti tanaman bunga pukul delapan (turnea sabulata), air mata pengantin (antigon leptosus), bayam duri (amarantus spinosus), belimbingan (oxalis barrelierri) dan patikan (euphorbia hirta), Kemudian pengendalian hama secara kimia (khemis) menngunakan beberapa jenis pestisida seperti decis2,5 EC, Sherpa 50 
$\mathrm{EC}$, ripcord $5 \mathrm{EC}$, matador $25 \mathrm{EC}$, lanate $25 \mathrm{WP}$, amitras, deltha metrin dan sevidol 4/4G.

\section{Kesimpulan}

Jenis hama pada TBM (Tanaman belum menghasilkan) yang ditemukan di PTPN IV Dolok Sinumbah Sumatera Utara ada 6 spesies yaitu Setothosea asigna, Calliteara horsfieldii Saunders, Metisa plana walker, Tirathaba mundella walker, Orytes rhinoceros, dan Tertacychus bimaculatus. Pengendalian hama dilakukan secara physic yaitu pengambilan pengutipan hama ulat, kepompong (pupa) dan pembersihan tempat berkembang biaknya. Secara Biologis menggunakan beberapa jenis tanaman inang bagi predator hama seperti tanaman bunga pukul delapan (turnea sabulata), air mata pengantin (antigon leptosus), bayam duri (Amarantus spinosus), belimbingan (Oxalis barrelierri) dan patikan (Euphorbia hirta), dan secara Kimia (khemis) menggunakan decis2,5 EC, Sherpa 50 EC, ripcord 5 EC, matador 25 EC, lanate 25 WP, amitras, deltha metrin dan sevidol 4/4G.

\section{Ucapan Terima Kasih}

Penulis menghargai dan mengucapkan terima kasih kepada PT.Perkebunan IV Dolok Sinumbah yang telah mendukung penelitian ini.

\section{Daftar Pustaka}

Ali, S.R.A., Najib, M.A., Mazmira, M., Masri, M dan Basri, M.W. 2012. Field Efficacy of MPOB Ecobac-1 (EC) for Controlling Bagworm, Pteroma pendula (Lepidoptera: Psychidae) Outbreak in Oil Palm Plantation. UMT 11th International Annual Symposium on Sustainability Science and Management 09th - 11th July 2012, Terengganu, Malaysia.

Fauzi, Y., Yustina E.Widyastuti.,Iman S., Rudi H. Paeru. 2012. Analisis dan Pemasaran Pemanfaatan Hasil Limbah Kelapa Sawit. Jakarta: Penebar Swadaya

Hakim, M. 2007. Kelapa Sawit, Teknis Agronomis dan Manajemennya. Lembaga Pupuk Indonesia. Jakarta, hal 295.

Hartanto, H. 2011. Sukses Besar Budidaya Kelapa Sawit. Citra Media Publishing.Yogyakarta.

Manik, E. B. 2012. Efektifitas Pengendalian Hama Ulat Api (S.asigna) Dengan Metode Fogging di Tanaman Kelapa Sawit di Pusat Penelitian Aek Pancur. Tugas Akhir Stipap Medan.

Mawikere J et al. 2007. Oryctes rhinoceros attack on Coconut tree in East Java. Euginia 13 (1) : 20-27. 
Nasution, A; Mardina, V; Wibowo S.G. 2021. Diagnosis makroskopik penyakit tanaman yang disebabkan mikroorganisme patogen. Serambi journal of agricultural technology, 1(1):1-7.

Pahan, I. 2008. Panduan Lengkap Kelapa Sawit. Jakarta: Penebar Swadaya. Jakarta 404 hal.

Pusat Penelitian Kelapa Sawit (PPKS). 2002. Prosedur Operasional Baku Pembibitan Kelapa Sawit. Medan : Pusat Penelitian Kelapa Sawit.

Rindarkoko, Y. 2012. Intensitas Serangan Hama Tanaman Kelapa Sawit (Elaeis quineensis Jacq) Pada Beberapa Umur Tanaman Di Perkebunan Rakyat Desa Panggungrejo Kecamatan Panggungrejo Kabupaten Blitar.Skripsi.Jurusan Hama dan Penyakit Tumbuhan Fakultas Pertanian Universitas Jember. Siradjuddin, I. 2015. Dampak Perkebunan Kelapa Sawit Terhadap Perekonomian Wilayah di Kabupaten Rokan Hulu. Jurnal Agroteknologi, Volume 5 No 2.

Sitorus Y.R dan Mardina, V. 2020. Karakteristik kimia dari pengolahan limbah cair kelapa sawit PTPN Y. Jurnal Enviroment Science, 4 (2): 58 - 66.

Surbakti, B.J., Mardina V, Fadhliani. 2020. Karakteristik limbah cair hasil pengolahan sistem lumpur aktif pada pabrik kelapa sawit PTPN II Tanjung Morawa, Kebun Sawit Seberang. Jurnal Biologica Samudra, 2 (2): 95 - 102

Yuna, R dan Mardina V. 2019. Pengujian Karakteristik Kimia pada Limbah Cair Kelapa Sawit di Pabrik X. Jurnal Biologica Samudra, 1 (1): 1 - 8. 